The use of communicative language teaching approach in the teaching of communication skills courses in Tanzanian universities

Nyinondi, Onesmo Simon

Sokoine University of Agriculture, Tanzania (onesmon@hotmail.com)

Mhandeni, Abdulkarim Shaban

Sokoine University of Agriculture, Tanzania ( $\underline{\text { amhandeni@gmail.com) }}$

Mohamed, Hashim Issa

Sokoine University of Agriculture, Tanzania (mohhashim@gmail.com)

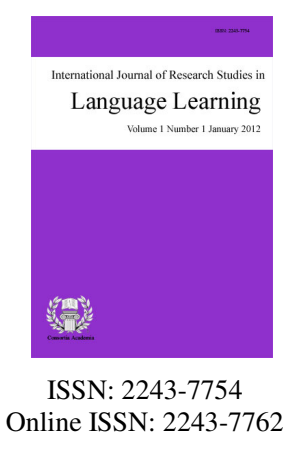

OPEN ACCESS

\begin{tabular}{lll} 
Received: 11 May 2016 & Revised: 16 July 2016 & Accepted: 18 July 2016 \\
Available Online: 11 August 2016 & DOI: $10.5861 /$ ijrsll.2016.1528 & \\
\hline
\end{tabular}

\title{
Abstract
}

English has been used as a medium of instruction in secondary schools and universities in Tanzanian. Pedagogical practice in these levels has however, continued to generate huge challenges in the education system. Considerable amount of time is wasted by students grappling with the language of instruction instead of learning their other subjects. In universities, Communication Skills (CS) course was introduced primarily to enable students apply the existing knowledge of English to particular skills in order to respond to specific academic communicative needs in their disciplines. But, students' existing knowledge of English at the moment of joining the university, is often so inadequate to have any meaningful application of such knowledge. This happens against the backdrop of a paradigm shift where communicative language teaching (CLT) has currently permeated pedagogical practice globally. In the current study, the researchers undertook to investigate how universities in Tanzania have been able to implement Communicative Language Teaching (CLT) approach in the teaching of Communication Skills Courses. Researchers used qualitative study design through interviews of students and staff, focus group interviews with staff, documentary analyses of CS courses, and classrooms Observations. The findings reveal that inadequacy of CS as competency based course, diversity of students in language abilities and disciplines, localization of teaching material, and instructors' authority working against students' autonomy have been compromising students' development of academic communication competence. The study recommends for a scrutiny of CS curricular to make them more competent based, specific and connected to communication rather than linguistic minutia.

Keywords: communicative language teaching; communication skills; universities; English language 


\section{The use of communicative language teaching approach in the teaching of communication skills courses in Tanzanian universities}

\section{Introduction}

In the Tanzanian education and training policy, which was in operation up to 2015, English has been (and is still) used as a medium of instruction in post primary education; it is also taught as a subject from primary 3 . In reality however, even where English is used as a medium of instruction, pedagogical practice has so far generated huge challenges in that the language is not used in communication. Additionally, students are taught about English language, and are not given opportunities to use the language communicatively. Furthermore, English is an official second language, but as shown above its official status is significant only in the field of education as the medium of instruction. Outside the education system, English is the language of the minority group spoken by only a $15 \%$ percentage of the population (see Rubagumya, 1990). In the wider community English use is limited to international relations and trade; business; tourism; mass media (e.g. newspapers, Radio and TV stations); higher courts of law; and information technologies (e.g. internet services, which are still concentrated in the urban areas). The limited use of the language in public domains in itself raises questions as to whether English qualifies to be an official second language in the country.

There is a plethora of literature documenting the problems of communication in English in Tanzania at secondary school level (see Rubagumya, 1990; Qorro, 1999, Brock-Utne, Desai, \& Qorro, 2003, 2005). Therefore, in the Tanzanian classroom; considerable amount of time is wasted by students grappling with the language of instruction instead of learning their other subjects.

In universities, Communication Skills course was introduced primarily to enable students apply the existing knowledge of English to particular skills needed for specific departments or disciplines in order to respond to specific academic communicative needs in those disciplines. But, the students' existing knowledge of English at the moment of joining the university, in most cases, is too inadequate to have any meaningful application of such knowledge. This is despite that in the pre-university education; students undergo 6 years of instruction in English (i.e. 4 and 2 years of secondary and high school education respectively). And as we have seen, English is taught as a subject from year 3 of the 7 years of primary school education (see Tanzanian education and training policy (URT, 1995; URT, 2015).

Thus, Communication Skills course in these universities has often been two tier modules which are grammatical skills and study skills in the realization that students' weaknesses were (and still are) at two levels, the level of grammatical competence GC - the knowledge of a language that accounts for the ability to produce sentences in a language. In other words, the knowledge of building blocks of sentences (e.g. parts of speech, tenses, phrases, clauses, sentence patterns); and the level of communicative competence, that is, the ability to use language in meaningful communication (see Richards, 2006; Savage, Bitterlin, \& Price, 2010).

Despite this arrangement, university students had been increasingly failing to cope with the technical and scholastic demand made on their use of language as students. This scenario was thought to have negative impacts on the university delivery systems, and thus undermining university efforts of offering quality education to its graduate, especially because most of these graduates fail to adequately access such education because of these language and communication related challenges.

Studies which have been done so far (i.e Brock-Utne, Desai, \& Qorro, 2003, 2005; Komba, 2015; Mohamed, 2006; Ndoloi, 1994; Rugemalira, 1990), have been focusing on students' language and communication problems generally, that is, how successful or unsuccessful has English language teaching been in secondary schools and universities. Little is known on how Communicative Language Teaching Approach has been used at the 
universities in the teaching of Communication Skills courses. The current study wished to answer one of the most intriguing questions, why is it that Communicative Language Teaching Approach in the teaching of Communication Skills (CS) courses offered in many universities in the country do not seem to pay any dividends?

\section{Trends in ELT worldwide}

The field of English Language Teaching (ELT) worldwide has undergone significant changes in the past thirty years toward a more communicative direction. The main focus of ELT has changed from what the teacher does to what the learners will be able to do. The changing trends saw a paradigm shifts in the positions and beliefs about, the nature of language, the nature of language learning and the applicability of both in pedagogical setting. Earlier views of ELT focused on the mastery of Grammatical Competence. Language learning was viewed as a process of mechanical habit formation. Good habits are formed by having students produce correct sentences and not through making mistakes. But, these approaches did not make students competent communicatively, in that students were able to master the rules of sentence formation in a language and still not be very successful in using the language for meaningful communication.

In this regard, current approaches shifted a focus from mastery of grammatical competence to communicative language teaching. Since its inception in the 1970 until recently, there has never been a consensus as to how CLT should be approached, however there is now a general agreement as to what features Communicative approach should be based on whereby teachers can design communication-oriented language teaching (COLT) suited to his or her own specific context.

Accordingly, the underlying philosophy and practice of ELT through communicative approach based on four features as follows:

$>$ CLT- a set of principles about the goals of language teaching;

$>$ How learners learn a language,

The kinds of classroom activities that best facilitate learning, and

$>\quad$ Roles of teachers and learners in the classroom (see Richards, 2006).

These features are elaborated as follows; as for feature number one, CLT sets as its goals the teaching of Communicative Competence (CC), that is, ability to use the language for meaningful communication. CC includes a range of language knowledge such as how to use a language for a range of different purposes and functions, how to vary our use of language according to the setting and the participants (e.g. the use of formal v/s informal speech, the use of appropriate language for written versus spoken communication), how to produce and understand different types of texts (e.g. narratives, reports, interviews, conversations, and many others), and how to maintain communication despite having limitations in one's language knowledge, for instance, through using different kinds of communication strategies (see Richards, 2006; Brown, 2006).

As for how learners learn a language, CC focuses on interaction between the learner and the users of the language, collaborative creation of meaning, creating meaningful and purposeful interaction through language, negotiation of the meaning as the learner and his or her interlocutor arrive at understanding (Richard \& Rodgers, 2014). Richard and Rogers also add that learning through attending to the feedback learners get when they use the language, paying attention to the use of the language one hears (the input) and trying to incorporate new forms into one's developing CC and trying out and experimenting with different ways of saying things.

One of the goals of CLT is to develop fluency focused activities. Fluency is considered as the natural occurring when a speaker engages in meaningful interaction (Richards, 2006). Current ELT curricula recognize the nature of language acquisition to be spiral or non-linear, that is, learners may encounter a language concept 
many times before fully grasping it and thus benefitting from repeated exposure to related concepts (Richard, 2008a). Furthermore, the learning of English is seen not as an end in itself, but as a means to gain access to content in one's particular area of interest (English for Specific Purposes), as is the case at universities in Tanzania where students must be able to use English in order to complete academic tasks in their various courses of study (English for Academic Purposes).

As for the roles of teachers and learners, $\mathrm{CC}$ requires teachers to assume a role of facilitator and monitor. Rather than being a model for correct speech and writing, and one with the primary responsibility of making students produce plenty of error free sentences, the teacher had to develop a different view of learners' errors and her/his own role in facilitating language learning, learners have to participate in classroom activities based on a cooperative approach to learning, listening to peers in group or pair work tasks rather than relying on the teacher for a model, and taking greater degree of responsibility for their own learning. Lastly in communicative language teaching, apart from increased student participation, there is greater learner autonomy, which puts him/her at the centre of teaching and learning of the language (see Richards, 2006; Jones, 2007, Brown, 2006).

As stated earlier, CLT framework has currently permeated pedagogical practice in the ESL globally. How universities in Tanzania have been able to use CLT framework in the teaching of Communication Skills Courses is yet to be established.

In the current study and as the main objective, the researchers undertook to investigate how universities in Tanzania have been able to implement Communicative Language Teaching (CLT) approach in teaching of Communication Skills Courses. Specifically the study wished to explore factors influencing the use of CLT in the Tanzanian university classroom, focusing on the course content, students and instructors' relationship, Language learning environment and teaching materials. Lastly, the study suggests the mechanisms which could be adopted to address students' communication problems in Tanzania within the CLT framework.

\section{Methodology}

\subsection{Participants}

The data for this study were collected at Sokoine University of Agriculture (SUA) in Tanzania as a case study from 2013 to 2015 following a qualitative research design. Experience shows that the situation that exists at SUA is an epitome of what happens in other universities in Tanzania.

\subsection{Sampling procedure}

Ethical considerations - This study followed standard procedures for social research, whereby permission was sought from the university and granted. All participants in the study willingly agreed to participate and confidentiality of the participants was strictly observed.

Sampling techniques - The study involved 16 heads of departments purposefully selected from departments across the university, eighty (80) students from different degree programmes. These involved 10 clusters each involving 8 participants who were randomly selected and 50 course instructors, whereby 15 CS instructors and 35 instructors from other disciplines were purposefully selected and organized into three clusters.

Instruments - Several tools were used to collect data and these include face to face interviews, focus group discussion, and documentary analysis and direct observation. Face to face interviews were mainly administered to heads of departments because they seem to have an in depth insight regarding areas of special language needs for their students. Focus group discussions involved three clusters 2 had 15 participants each and one had 20 participants. One of the cluster (15 members) involved CS instructors, and the other two one 15 members and 20 members involved instructors from other disciplines. The focus group discussions were conducted to instructors to explore issues on course structure and implementation. 
Motivational changes of learners in a traditional context of English education

Documentary analyses of current curricula for Communication Skills courses. This involved a review of two curriculum documents and which were evaluated in the light of the evaluative framework as identified by Jacobs and Farrell (2003). Jacobs and Farrell identified eight features which a CLT curriculum should reflect, and these constitute the criteria against which a communicative curriculum can be evaluated. The eight features include, learner autonomy, social nature of learning, curricular integration, focus on meaning, diversity, thinking skills, alternative assessment, and teachers as co-learners (2003, p. 10). Direct classrooms observations involved four instructors each of who were observed twice making a total of 8 classroom sessions.

\subsection{Study design and data analysis method}

This study followed a case study research design where data were collected from a sample of respondents from a defined population as explained above. Data were analyzed using qualitative data analysis methods whereby thematic analysis approach was used.

\section{Findings and discussion}

The emerging issues in this section were classified into the following categories, adequacy of Communication Skills as competency based course, diversity of students' in language and disciplinary backgrounds, lack of supportive language learning environment, teaching material, and students' autonomy versus instructors' authority.

\subsection{Communication Skills course content}

This particular component of the study is addressed by the interpretation of data obtained through a review of communication Skills Curriculum and information obtained from Focus Group Discussion with communication skills instructors. At the university under study, communication course is offered on the assumption that students already have some knowledge of English. This is for the simple reason that English is the medium of instruction in Tanzania from Secondary school education and above. One of the main weaknesses pointed out in the existing Communication Skills syllabi is having discrete topics which are not contextualized to the students local environment, putting much emphasis on elements of grammar and focusing on receptive skills of listening and reading, and with only summative form of assessment. In this respect, the current curriculum has failed to meet the requirements of CLT curriculum on areas focusing on meaning, and alternative assessment.

Furthermore, the mode of teaching and learning as described in the course outline comprise lectures and seminars, that is, 35 lecture hours per week and 30 seminar hours per week; this arrangement clearly does not provide students with adequate opportunities to participate and practice English language communicatively. Within the CLT framework, classroom activities ought to reflect natural use of language, focus on achieving communication, require meaningful use of language, making use of communication strategies, produce language that may not be predictable, and seek to link language use to context. The arrangement also flouts Jacobs and Farrell's (2003) criteria of a CLT curriculum on learner autonomy and social nature of learning.

Secondly, the students' communication problems seem to oscillate between cognitive competencies (e.g. knowledge of the discipline) and linguistic competencies (knowledge of the disciplinary dialect). And as Ballard and Clanchy (cited in Taylor et al., 1988, p. 8) note, "in many instances ... it is very difficult to determine whether the origin of a student's illiteracy is primarily cognitive or primarily linguistic".

Other criticisms about CS course seem to be similar across universities, at the university of Dar es Salaam for example, where the course was first started, the course was criticized for lack of developing students' communicative competence; in that the course has failed to make students communicate better. Understandably, this argument has been made after seeing that despite University efforts, students' language problems have continued to blossom instead of receding. One reason for this, according to Roy-Campbell and Qorro was that the range of linguistic problems among students "were too vast to be dealt with in which students met three 
Nyinondi, O. S., Mhandeni, A. S., \& Mohamed, H. I.

times a week for a total of 60 hours during the entire academic year" (1997, p. 4). The context in which the course is offered at the University of Dar es Salaam epitomizes what happens in other universities in Tanzania, including the university under study. Currently, students at the university in the study take placement test, which is meant to filter out students who are linguistically and communicatively competent, and leave those who are proven to be weak to take the course. Although, experience shows that many students fail the test, often such a test has not been accurately able to indicate students' English language ability for them to excel in University studies. Students who test out in placement test often fail to excel when subjected to other language demands in their other subjects.

\subsection{Students' diversity in language and disciplinary backgrounds}

Another aspect is the current arrangement whereby the CS course draws students from a wide variety of disciplines and varied backgrounds in one classroom. As a result of this phenomenon, it appears that the course somehow carters for everybody, but satisfies none. Lecturers' observations during focus group discussions also attested to this reality. 'When we talk of Communication Skills morally we teach students to become members of a specific speech community.... We are not doing that just teaching (them) ah- general Communication Skills' (Focus group, 2015).

This phenomenon leads to two complex aspects; one, How can a Communication Skills course be able to address the language demands of students from as diverse disciplinary orientations as the ones found in universities in Tanzania? Any framework to be constructed for this purpose will put further demands on two aspects: First, as suggested by De Jong and Harper (2005), effective teaching practices of English requires teachers to have additional linguistic and cultural knowledge and skills and learn to apply these to curriculum planning, pedagogy, and assessment for ESL. This ought to enable them to offer specialized language and communication skills instruction in university classroom.

The second aspect is to have instructors with enough background to teach a specialized scientific academic communication class. The above arrangement is, so far, the most ideal but the one, which poses a bigger challenge for the CS course in its current framework at universities. In other words, the arrangement demands that other academic Departments enlist their support and work alongside instructors in the CS course. Such a framework has its own constraints to overcome. Notably, it entails motivating other Departments to realize that students' language problems are their responsibility too. Currently, there is lack of dialogue between the CS course instructors and the instructors in other academic Departments in the process of mentoring students in generic apprenticeship. In this respect, the CS course is unlikely to have any significant impact on students' academic writing process, even with the full implementation of CLT framework.

Mixing students from different disciplines and abilities also points back to the issues of academic literacy (see Lillis, 2000; Bakhtin in Lillis, 2001) theories, that is, though students are socially shaped, they are individuals with different experiences and backgrounds. It is for this reason that students' meaning making around academic literacy in Communication Skills is structured by such constructs as voices and identity.

This complex bundle of individual voices and identities structuring and shaping students' background experiences impacts profoundly on the students' pathways to proficiency in communication in their academic disciplines especially in situations where the existing English courses are also offered to very large classes, making it difficult for instructors to teach effectively (Bourdieu, et al., 1994),. Further, “... what we inherit from our social origins is not only a language, but inseparably- a relationship to language and specifically to the value of language" (Bourdieu et al., 1994, p. 21). Arguably therefore, some background experiences can conveniently classify some students as linguistically disadvantaged because " $\ldots$ a child spent in a world in which words tended to become the reality of things prepared him more to enter an intellectual world founded on the same principle than the child from a different family setting" (see Bourdieu et al., 1994, p. 21) (our addition in italics).

In the Tanzanian social context, therefore, the linguistically privileged home background or social origins 
Motivational changes of learners in a traditional context of English education

will have more requisite resources in English language learning. Accordingly, when such students are mixed with others who come from a relatively underprivileged linguistic background there are dangers that the communication skills acquisition demands of either group are unlikely to be met.

From the above discussions, the CS course at universities has been unable to address students' demands in terms of not only 'context of situation', that is, at the level of disciplinary language, but also in terms of 'context of culture', that is, at the level of broader students' cultural backgrounds and home or community experiences. This reality undermines the current CLT framework which recognizes the spiral or non-linear nature of language acquisition where, learners have the opportunity to encounter a language concept many times before grasping it fully and thus benefitting from repeated exposure to related concepts. This reality also goes contra to CLT framework which sees the learning of English not as an end in itself, but as a means to gaining access to content in one's particular area of interest (English for Specific Purposes), as is the case at universities in Tanzania where students must be able to use English in order to complete academic tasks in their various courses of study (English for Academic Purposes) (See Trends in ELT worldwide, this report).

Commenting on the CS course at one of the universities in Tanzania, Ndoloi alludes to the same phenomenon when he says, writing programmes 'have been the responsibility of' Communication Skills Units, which are "either autonomous or sections of Language Departments". And because of "the large number of students and their different requirements, these courses have been crash programmes involving issues of grammar, listening, speaking, and short paragraphs writing compressed into a few weeks" (1994, pp. 298-299). It should be noted, however, that the concept of large class has varied interpretations, according to countries or contexts. For instance, while in Bangladesh the maximum language class has 40 students (Ansarey, 2012), in Tanzania although in the policy documents the maximum language class size is 40 students (TAI, 2007), but in practice the average language class has 150 students. Ndoloi, notes further that even when these courses run along other specialized courses, they have followed a standard syllabus and the uniqueness of the students who join have been ignored; either they have been overlooked or the pressures facing the tutors have been either too much and they only have had to make do with what has been possible (Ndoloi, 1994, pp. 299-300).

\subsection{Lack of supportive language learning environment}

The university under study, as is the case in many other universities in Tanzania, currently lacks a supportive environment where classroom knowledge can be reinforced outside language classrooms. For example, in focus group interviews with lecturers and students, it was reported that consultations are often not conducted in English and English/Kiswahili code mixing are frequent in classroom interaction. Unlike what is stipulated in the Tanzanian education and training policy (URT, 1995; URT, 2015), we have seen that English is a medium of instruction in secondary and higher education (HE), the classroom practice in these levels is increasingly becoming English and bilingual medium.

This situation poses a constraint in achieving communicative competence which is one of the goals of CLT described above and which needs to have interaction between the learner and the users of the language, collaborative creation of meaning, creating meaningful and purposeful interaction through language, and negotiation of the meaning as the learner and his or her interlocutors arrive at understanding. This goal becomes increasing difficult to achieve in the Tanzanian context where English is not used outside the classroom and in the classroom the teacher remains the model of language production. Similar findings are reported in a study by Mohamed (2006) where when reporting reasons for lack of supportive language learning environment outside classroom some of the respondents attributed this trend to lecturers' attitude towards the use of language in Tanzanian context as is alluded to in this extract, '...the place of English in the Tanzania's social context should naturally be the classroom, 'Within the confines of the class...' (Mohamed, 2006, p. 186).

To this lecturer, this is what seems to be the interpretation of the medium of instruction, the 'institutionalization' of language for teaching purposes only. The use of such a language in the broader 
Nyinondi, O. S., Mhandeni, A. S., \& Mohamed, H. I.

communication outside the classroom is not necessary, neither is it desirable. Learning a language however is analogous to learning to play a sport. If the player only reads the rules, or only listens to people talk about how to play, or tries to play without knowing the rules, he/she will not be able to play the game. A good player comes to the field already knowing the rules of the game; she or he warms up and then plays with all of her or his energy. She or he takes risks, if she or he falls down, she or he stands up and tries again. Like playing a sport, learning a language requires a team. The player's team is his/her classmates, and the instructor is the referee or moderator. The moderator can remind the player of the rules and give him/her feedback, but the player needs to put in efforts and actively play the game (Lynch, 2015). The metaphor of playing a sport in learning a language is critical in CLT framework, which requires learners to take responsibility in their own learning. It is also crucial because playing a sport also facilitates knowing the rules of the sport. Also, critical here is the concept of teamwork; this is because no communication is done by single persons, once someone begins to speak or write someone else should be available to either listen or read the text; and this is where meanings are negotiated; in other words meanings are negotiated in real communication between two or more interlocutors.

It should be noted however, that in order to implement CLT successfully, there are other issues such as classroom physical environment, and application of technology among others. But since these factors have been being widely reported in earlier studies for years, the current study dealt with the use of English among students and among instructors per se.

As indicated in the preceding paragraph of this section, that one of the factors constraining the use of English for majority of the learners and their tutors is the fear of making mistakes when conversing in English. According to Lynch $(2015$, p. 2) “...mistakes are a natural part of language learning” One cannot feel ashamed or be afraid of making mistakes because these are "an opportunity to try something new. Take a risk and learn by doing." (p. 2) It is essential therefore that the playing ground be expanded beyond the classroom environment where classroom knowledge finds broader application and enhancement in real life communication.

\subsection{Perception on language and communication concepts}

One of the things observed in the current study was the misconception about language and communication concepts among instructors. Many instructors had the perception that communication was synonymous with language, others thought that there was a difference between communication and language but they could not explain exactly what the difference was. This misconception has had some adverse effects in the teaching of Communication Skills courses at universities in Tanzania. This is particularly because instructors from other disciplines thought that assisting in the teaching of communication was synonymous with the teaching of language, which they claimed to have lacked the expertise and therefore decline to participate. Language and communication though inseparable, the two concepts are fundamentally different. Thomson (as cited in Kobo, 2013, p. 11) clarifies the difference between language and communications in that, 'language is a set of systems, which interlinks with a range of social and psychological factors; the use of a set of systems in combination provide meaningful communication'. While communication on the other hand, is 'a transfer of information from one person to another in negotiating ideas through social interaction in which language is used as a means of that interaction' (Thomson as cited Kobo, 2013, p. 11).

\subsection{Training materials}

Another characteristic of current CLT curriculum places greater emphasis on securing or creating locally-contextualized materials, situations, themes, and the like so that students understand that English belongs to them for communication. Most importantly, these elements increase students' motivation to learn and participate in class activities. As observed by McCarten (2007), "Materials can help students in two broad areas: First, they need to present and practice in natural contexts the vocabulary that is frequent, current, and appropriate to learners' needs. Second, materials should help students become better learners of vocabulary by teaching different techniques and strategies they can use to continue learning outside the Classroom" (p. 19). 
However, one of the areas where the use of CLT has been problematic is the localization of training materials to suit students' linguistics needs in their local environment (See Richards 2006, Jacobs \& Farrell, 2003). This exercise has not been easy in the context of universities in Tanzania, first because it is rather demanding in terms of practical expertise required in developing such materials. Secondly, when such expertise is available, resources in producing such materials become a constraint, especially where administrative structures do not give priority to language based disciplines, as is the case in universities in Tanzania.

In view of the foregoing observation, instructors have resorted to the production of handouts, teaching manuals and compendia. The authoritative nature embodied in the construction, production and presentation of such materials (as absolute authority) encourage students to believe that handouts and compendia are the only relevant source of information around the given subject. Thus, students are denied opportunities to develop critical voices in interacting with such materials; but it is these critical voices that enable students to gain confidence in the command of the disciplinary language (see also Leibowitz \& Mohamed, 2000), which carries the given disciplinary knowledge.

This problem is further compounded by the questioning practices of some of the lecturers, who usually set questions around lecture notes or the compendia which have been prepared for students' use. This is likely to deny students the opportunities of bringing in some additional material when writing essay questions. The tension structuring lecture note taking practice at universities is best encapsulated in Lillis' observation that, the socio-discursive space, which is inhabited by student and tutors is fundamentally monologic, that is, "it is the tutor's voice that predominates, determining what the task is and how it should be done, without negotiating the nature of the expectations surrounding this task through dialogue with the student-writer" (Lillis, 2001, p. 75).

\subsection{Students'autonomy versus instructors' authority}

During class observation, dominance of lecturers' voice was quite frequent, because teaching methods, as we have seen, were predominantly lecture method. Ellis and Karavas-Doukas (cited in Ansarey, 2012) for example, made similar observed that one of the main problems in the use of CLT in Vietnam and Greece was that English language teachers were still embracing teacher-centered approach which is contrary to what CLT espouses, that is, student-centered approach, According to Jones (2007), the role of teachers as facilitator and monitor and that of learners, as individuals who take responsibility for their own learning, as demanded by CLT, have either wittingly or unwittingly been ignored. The Tanzanian social cultural context has a role to play in structuring teacher -students' relationship in a classroom. Generally, Tanzania is a high powered society. In high powered cultures social distance between superiors and subordinates is also very high (see Sen, 2005). In such cultural contexts the views, ideas and opinions of those who are lower in social position or rank would often be ignored. It is the superiors who assume dominant position in interaction and whose views must be followed even where such views are clearly controversial.

The predominance of tutors' voice in a communicative practice of higher education is constructed around authority vested on the lecturers. Privileged access to English language and communication is one of the social resources on which power is based (cf. van Dijk, 1993) among lecturers. The students-lecturers relationship is indexical of the potency in which this power and dominance construct and reconstruct themselves and hence denies students meaningful participation in classroom learning, which according to Bamba's (2012) observation, students have talents and therefore they need to be given opportunities to express them. Bamba also believes that organizing small group work can help students have other perspectives of a given topic, and build new understanding by confronting their ideas with those of other students.

\section{Conclusion and Pedagogical implications}

As earlier stated, despite the efforts made by many universities in Tanzania in offering CS courses as mandatory to first year students, the courses have had little impact in enhancing students' language abilities 
neither have they improved their participation in academic disciplines despite the paradigm shift from earlier approaches to CLT which currently widely practiced in ELT. In this respect recommendations are made in the following aspects:

As for the CS curricula; as is the case with any language curricular, objectives need to be more specific and connected to communication and skills rather than linguistic minutia. In addition, the outcomes of a language curriculum should include critical thinking skills as well as discipline-specific content, and whose assessment tools would reflect students' communicative competencies acquired over time.

As for students diversity in disciplinary and language background as stated earlier; this requires that instructors in a language course in collaboration with individual departments develop communication instruction courses, which address the language demands of the courses in the Departments concerned. Firstly, language instructors should specialize in disciplinary knowledge and that scientific academic language be involved in the teaching of these courses. Secondly, other instructors need to be made aware that language and communication is not the same thing. Teaching Language may require technical linguistic competence on the part of the instructor, but teaching communication may not require that technical linguistics paraphernalia, it just requires instructors to have classroom interaction with students in a communicative way as espouse in the CLT framework.

The role of teaching and using English should not be left to the language instructors only. In addition to correcting students' writing during marking their assignments, instructors in other disciplines should also communicate with students in English outside classrooms and in contexts other than academia. To achieve this, instructors should change their mindset regarding students and lecturers' roles in the classroom and outside classroom. To this end, it is clear that instructors in other disciplines should realize that they have a responsibility of addressing students' communication problems and universities should create the learning environment where English is used in such a way that cognitive academic language proficiency (CALP) could adequately be achieved among students.

Language class sessions should be more student-centred and communicatively based. More emphasis and class time should be spent on practicing and using the language skills taught as opposed to giving lectures about language. In preparing English language teachers, we have to ensure that student teachers are provided with a repertoire of skills, techniques, and necessary theoretical insights to enable them make principled decisions in the best interests of the particular pupils/students they teach. Finally, the goals of CLT should continue to influence language teachers whatever new approaches succeed it: teachers have to teach language so that learners are better able to use it in the full range of social situations.

\section{References}

Ansarey, D. (2012). Communicative language teaching in EFL contexts: Teachers attitude and perception in Bangladesh. ASA University Review, 6(1), 61-78.

Ballard, B., \& Clanchy, J. (1988). Literacy in the university: An 'anthropological' approach. In G. Taylor, B. Ballard, V. Beasley, H. Bock, J. Clanchy, \& P. Nightingale (Eds.), Literacy by degree (pp. 7-23). Milton Keynes: Open University Press.

Bamba, M. (2012). Seeking effective approaches to teaching large EFL classes in the ivory coast. Unpublished Thesis, Indiana University of Pennsylvania.

Bourdieu, P., \& Jean-Claude, P. (1994). Introduction: Language and relationship to language in the teaching situation. In P. Bourdieu, P. Jean-Claude, \& M. De Saint Martin (Eds.), Academic discourse: Linguistic misunderstanding and professorial power (pp. 1-34). The Hague: Polity Press in association with Blackwell Publishers Ltd.

Brock-Utne, B., Desai, Z., \& Qorro, M. (Eds.). (2003). Language of instruction in Tanzania and South Africa. Dar-es-Salaam: E\&D.

Brock-Utne, B., Desai, Z., \& Qorro, M. (Eds.). (2005). Language of instruction in Tanzania and South Africa. 
Dar-es-salaam: E\&D.

Brown, S. (2006). Teaching listening. New York: Cambridge University Press.

De Jong, E. J., \& Harper, C. A. (2005). Preparing mainstream teachers for English-language learners: Is being a good teacher good enough? Teacher Education Quarterly.

Jones, L (2007). The student-centered classroom. New York: Cambridge University Press.

Jacobs, G. M., \& Farrell, T. S. C. (2003). Understanding and implementtng the CLT (Communicative Language Teaching) paradigm. RELC Journal, 34(1), 5-30. http://dx.doi.org/10.1177/003368820303400102

Kombo, M. J. (2013). Communicative language teaching: A comparison of the Lesotho form E (English) and South African Grade 12 FAL (English) curricula. Unpublished Masteral thesis, Stellenbosch University.

Komba, S. C. (2015). The perceived importance of communication skills courses among university students: The case of two universities in Tanzania. International Journal of Education and Research, 3(2), 497-508.

Leibowitz, B. (2000). The importance of writing and teaching writing in the academy. In B. Leibowitz \& Y. Mohamed (Eds.), Routes to writing in Southern Africa (pp. 15-41). Cape Town: Silk Road International Publishers.

Lillis, T. M. (2001). Student writing: Access, regulation, desire. New York: Routledge.

Lynch, R. (2015). SC 100 Student activity book. Language and Communication Skills Compendium. Morogoro: SUA.

McCarten, J. (2007). Teaching vocabulary: Lessons from the corpus, lessons for the classroom. New York: Cambridge University Press.

Mohamed, H. I. (2006). Academic writing as social practice: A critical discourse analysis of student writing in higher education in Tanzania. Unpublished Doctoral thesis. University of the Western Cape. Cape Town.

Ndoloi, D. B. (1994). Writing like Tanzanians: Investigating the writing of first year students. Unpublished Doctoral thesis, Lancaster University. Lancaster.

Qorro, M. A. S. (1999). A qualitative study on the teaching and learning of writing in English in Tanzania secondary schools in relation to the writing requirements of tertiary education. Unpublished Doctoral thesis, University of Dar es Salaam. Dar es Salaam.

Richard, J. C., \& Rodgers, T. S. (2014). Approaches and methods in language teaching. Cambridge: Cambridge University Press.

Richards, J. C. (2006). Communicative language teaching today. New York: Cambridge University Press.

Richards, J. C. (2008a). Moving beyond the plateau from intermediate to advanced levels in language learning. New York: Cambridge University Press.

Richards, J. C. (2008b). Teaching listening and speaking: From theory to practice. New York: Cambridge University Press.

Roy-Campbell, Z. M., \& Qorro, M. A. S. (1997). Language crisis in Tanzania: The myth of English versus education. Dar es Salaam: Mkuki na Nyota.

Rubagumya, C. M. (1990). Language use in Tanzania. In C. M. Rubagumya (Ed), Language in education in Africa: A Tanzanian perspective (pp. 5-14). Clevedon: Multilingual Matters.

Rugemalira, J. M. (1990). The communication skills unit and the language problem at the University of Dar es salaam. In C. M. Rubagumya (Ed), Language in education in Africa: A Tanzanian perspective (pp. 105-122). Clevedon: Multilingual Matters.

Savage, K. L, Bitterlin, B., \& Price, D. (2010). Teaching grammar in adult ESL programs. New York: Cambridge University Press.

Sen, L. (2005). Communication skills. New Delhi: Prentice-Hall of India.

Tanzania Institute of Education. (2007). Curriculum for ordinary level secondary education in Tanzania. Dar es Salaam, Ministry of Education and Vocational Training.

United Republic of Tanzania. (1995). Education and training policy. Dar es Salaam, Ministry of Education and Culture.

United Republic of Tanzania. (2015). Education and training policy. Dar es Salaam, Ministry of Education and Vocational Training.

Van Dijk, T. A. (1993). Discourse and society. London: SAGE. 
Nyinondi, O. S., Mhandeni, A. S., \& Mohamed, H. I. 